\title{
Comment on: interest of b-blockers in patients with right ventricular systemic dysfunction
}

Keywords: Paediatric cardiology; cardiac magnetic resonance imaging; brain natriuretic peptide

Received: 13 December 2010; Accepted: 14 March 2011; First published online: 19 April 2011

Dear Sir,

Bouallal et $\mathrm{al}^{1}$ have touched on an important therapeutic dilemma in patients with reduced right ventricular function supporting systemic circulation. As they have mentioned, there exist no randomised clinical trial showing the benefit of beta-blockade in this group of patients. Hence, the recommendation to treat these patients with betablockers remains without any evidence.

We recently published the results of a prospective, randomised, double-blind, placebo-controlled trial of beta-blockade on patients with operated tetralogy of Fallot and could not demonstrate a significant positive effect on right or left ventricular size and function, cardiorespiratory exercise capacity, or quality of life. ${ }^{2}$

Despite there being fundamental differences in the pathophysiology of right ventricular volume overload - e.g. in post-operative patients with tetralogy of Fallot - and right ventricular pressure overload in patients with the morphologic right ventricle functioning as the systemic ventricle, obviously the effect of beta-blockade on the right ventricle seems to be different from the effect on the left ventricle. ${ }^{3}$

We would like to address several methodological concerns in the paper by Bouallal et $\mathrm{al}^{1}$. There is no established gold standard for non-invasive assessment of the right ventricle. The most reliable method is cardiac magnetic resonance imaging. Radionuclide ventriculography is an alternative method for this purpose, but it is less reliable than cardiac magnetic resonance imaging, especially in patients with right ventricular overload after surgery for congenital cardiac disease. Nichols et al ${ }^{4}$

Correspondence to: K. Norozi, MD, FRCPC, Division of Paediatric Cardiology, Department of Paediatrics, University of Western Ontario, 800 Commissioners Road East, PO Box 5010, London, Ontario, N6A 5W9, Canada. Tel: +1 519 6858500 ext. 56062; Fax: +1 519685 8156; E-mail: kambiz.norozi@ lhsc.on.ca therefore recommend that cardiac magnetic resonance imaging should be the first choice for evaluating patients with congenital cardiac disease. In the paper published by Bouallal et $\mathrm{al}^{1}$, the assessment of right ventricle (pre- and post-beta blocker therapy) was done based on cardiac magnetic resonance imaging (in 10 patients) and Radionuclide ventriculography (in eight patients). Despite cardiac magnetic resonance imaging showing no change in right ventricular ejection fraction, Radionuclide ventriculography showed an improvement in ejection fraction from $41 \%$ to $49 \%$ ( $p=0.031$ ). Including two different methods for assessment of right ventricular function is per se problematic, but the question remains which method is more reliable and which results should be emphasised. The neurohumoral status of these patients remained unchanged, as reflected by the brain natriuretic peptide level, and hence it is difficult to attribute the improvement in ejection fraction as measured by Radionuclide ventriculography to remodelling of the right ventricular myocardium due to beta blockade.

Despite the study showing some improvement in subjectively felt physical activity, based on the New York Heart Association classification and Ability index, objectively measured cardiopulmonary capacity remains unchanged. Owing to the nature of study (not placebo controlled), it is impossible to rule out a placebo effect.

If there remains a positive clinical effect that is not explained by better myocardial function or exercise capacity, the question is what it is. In our opinion, these beneficial effects that we also observed in our placebo-controlled study may be caused by effects of beta-blocker therapy on the autonomic nervous system. Probably these effects could potentially be revealed by analysis of heart rate variability. Unfortunately, these data are not available in patients with congenital cardiac disease.

Last but not least, although appropriate statistical methods were employed, the small number of 
patients remains a concern, but the bigger question is whether the changes are clinically meaningful and/or generalisable.

\section{Kambiz Norozi ${ }^{1,2}$, Herschel C. Rosenberg ${ }^{1}$ Reiner Buchborn ${ }^{3}$ ${ }^{1}$ Department of Paediatrics London Health Sciences Centre University of Western Ontario London, Canada \\ ${ }^{2}$ Departments of Paediatric Cardiology and Intensive Care Medicine}

Medical School Hannover, Hannover, Germany ${ }^{3}$ Department of Paediatrics, Caritas Krankenhaus University of Wuerzburg Bad Mergentheim Germany

\section{References}

1. Bouallal R, Godrat F, Francart C, Richard A, Foucher-Hossein C, Lions C. Interest of b-blockers in patients with right ventricular systemic dysfunction. Cardiol Young 2010; 20: 615-619.

2. Norozi K, Bahlmann J, Raab B, et al. A prospective, randomized, double-blind, placebo controlled trial of beta-blockade in patients who have undergone surgical correction of tetralogy of Fallot. Cardiol Young 2007; 17: 372-379.

3. Haddad F, Doyle R, Murphy DJ, Hunt SA. Right ventricular function in cardiovascular disease, part II: pathophysiology, clinical importance, and management of right ventricular failure. Circulation 2008; 117: 1717-1731.

4. Nichols K, Saouaf R, Ababneh AA, et al. Validation of SPECT equilibrium radionuclide angiographic right ventricular parameters by cardiac magnetic resonance imaging. J Nucl Cardiol 2002; 9: 153-160. 